\title{
Access to specialist gastroenterology care in Canada: Comparison of wait times and consensus targets
}

\author{
Desmond Leddin MB FRCPC MRCPI MSC ${ }^{1}$, David Armstrong MB BChir MA FRCPC FACG AGAF FRCP(UK) ${ }^{2}$, \\ Alan NG Barkun MD CM FRCPC FACP FACG MSc ${ }^{3}$, Ying Chen $\mathrm{MSc}^{2}$, Sandra Daniels MSc ${ }^{4}$, \\ Roger Hollingworth MD FRCPC ${ }^{5}$, Richard H Hunt MB FRCPC FACG FRCPEd ${ }^{2}$, William G Paterson MD FRCPC
}

\begin{abstract}
D Leddin, D Armstrong, ANG Barkun, et al. Access to specialist gastroenterology care in Canada: Comparison of wait times and consensus targets. Can J Gastroenterol 2008;22(2):161-167.
\end{abstract}

BACKGROUND: Monitoring wait times and defining targets for care have been advocated to improve health care delivery related to cancer, heart, diagnostic imaging, joint replacements and sight restoration. There are few data on access to care for digestive diseases, although they pose a greater economic burden than cancer or heart disease in Canada. The present study compared wait times for specialist gastroenterology care with recent, evidence-based, consensus-defined benchmark wait times for a range of digestive diseases.

METHODS: Total wait times from primary care referral to investigation were measured for seven digestive disease indications by using the Practice Audit in Gastroenterology program, and were benchmarked against consensus recommendations.

RESULTS: Total wait times for 1903 patients who were undergoing investigation exceeded targets for those with probable cancer (median 26 days [25th to 75 th percentiles eight to 56 days] versus target of two weeks); probable inflammatory bowel disease (101 days [35 to 209 days] versus two weeks); documented iron deficiency anemia (71 days [19 to 142 days] versus two months); positive fecal occult blood test ( 73 days [36 to 148 days] versus two months); dyspepsia with alarm symptoms (60 days [23 to 140 days] versus two months); refractory dyspepsia without alarm symptoms ( 126 days [ 42 to 225 days] versus two months); and chronic constipation and diarrhea (141 days [68 to 264 days] versus two months). A minority of patients were seen within target times: probable cancer (33\% [95\% CI 20\% to 47\%]); probable inflammatory bowel disease (12\% [95\% CI 1\% to $23 \%]$ ); iron deficiency anemia (46\% [95\% CI 37\% to 55\%]); positive occult blood test (41\% [95\% CI 28\% to 54\%]); dyspepsia with alarm symptoms (51\% [95\% CI 41\% to 60\%]); refractory dyspepsia without alarm symptoms (33\% [95\% CI 19\% to 47\%]); and chronic constipation and diarrhea (21\% [95\% CI $14 \%$ to $29 \%]$ ).

DISCUSSION: Total wait times for the seven indications exceeded the consensus targets; $51 \%$ to $88 \%$ of patients were not seen within the target wait time. Multiple interventions, including adoption of evidence-based management guidelines and provision of economic and human resources, are needed to ensure appropriate access to digestive health care in Canada. Outcomes can be evaluated by the 'point-of-care', practice audit methodology used for the present study.

Key Words: Access; Benchmark; Digestive disease; Health care; Recommendation; Target; Wait time

\section{Accès à la médecine de spécialité en gastroentérologie au Canada : Comparaison des temps d'attente actuels et souhaités}

HISTORIQUE : Pour améliorer la prestation des soins de santé qu'exigent le cancer, la maladie cardiaque, les épreuves d'imagerie diagnostique, les prothèses articulaires et la correction de la vue, l'accent a été placé sur le contrôle des temps d'attente et la définition des objectifs de soin. On dispose de peu de données sur l'accès aux soins pour les maladies digestives, bien qu'elles représentent un fardeau économique plus lourd que le cancer ou la maladie cardiaque au Canada. La présente étude comparait les temps d'attente pour une consultation en gastroentérologie aux temps d'attente souhaitables récemment établis par voie de consensus et fondés sur les preuves pour diverses maladies digestives.

MÉTHODES : Les temps d'attente totaux entre une demande de consultation et des examens plus approfondis ont été mesurés pour sept maladies digestives, au moyen du programme PAGE (pour Practice Audit in Gastroenterology) et ont été comparés aux recommandations consensuelles.

RÉSULTATS : Les temps d'attente totaux pour 1903 patients qui devaient subir des examens plus approfondis ont dépassé les limites fixées pour les sujets atteints d'un cancer probable (temps médian 26 jours [du $25^{\mathrm{e}}$ au $75^{\mathrm{e}}$ percentile, huit à 56 jours]) comparativement à un objectif fixé à deux semaines); maladie inflammatoire de l'intestin probable (101 jours [35 à 209 jours] vs deux semaines); anémie ferriprive documentée ( 71 jours [19 à 142 jours] vs deux mois); test de dépistage de sang fécal occulte positif ( 73 jours [38 à 148 jours] vs deux mois); dyspepsie et symptômes alarmants ( 60 jours [23 à 140 jours] vs deux mois); dyspepsie rebelle sans symptômes alarmants (126 jours [42 à 225 jours] vs deux mois) et constipation et diarrhée chroniques (141 jours [68 à 264 jours] vs deux mois). Une minorité de patients ont été vus à l'intérieur des délais souhaitables : cancer probable (33\% [IC à 95\%, $20 \%$ à $47 \%$ ); maladie inflammatoire de l'intestin probable (12\% [IC à $95 \%$, $1 \%$ à $23 \%$ ); anémie ferriprive (46\% [IC à $95 \%$, $37 \%$ à $55 \%$ ); test de sang occulte positif (41 \% [IC à $95 \%, 28 \%$ à $54 \%$ ]); dyspepsie avec symptômes alarmants (51 \% [IC à $95 \%, 41 \%$ à $60 \%$ ]); dyspepsie rebelle sans symptômes alarmants (33 \% [IC à $95 \%, 19 \%$ à $47 \%$ ]) et constipation et diarrhée chroniques (21\% [IC à $95 \%, 14 \%$ à $29 \%$ ]).

DISCUSSION : Les temps d'attente totaux pour les sept indications ont excédé les objectifs souhaitables; de $51 \%$ à $88 \%$ des patients n'ont pas été vus à l'intérieur des intervalles établis par consensus. Il faudra mettre en œuvre plusieurs interventions, dont l'adoption de directives de prise en charge fondées sur des preuves, et consacrer des ressources économiques et humaines suffisantes pour assurer un accès en temps opportun à la médecine de spécialité en gastroentérologie au Canada. Les résultats peuvent être vérifiés au moyen de la méthodologie d'évaluation de la pratique aux points de service utilisée pour la présente étude.

${ }^{1}$ Division of Gastroenterology, Dalhousie University, Halifax, Nova Scotia; 2Division of Gastroenterology, McMaster University, Hamilton,

Ontario; ${ }^{3}$ Division of Gastroenterology, McGill University, Montreal, Quebec; ${ }^{4}$ Canadian Association of Gastroenterology, Oakville; ${ }^{5}$ Division of Gastroenterology, The Credit Valley Hospital, Mississauga; ${ }^{6}$ Division of Gastroenterology, Queen's University, Kingston, Ontario

Correspondence: Dr Desmond J Leddin, Queen Elizabeth II Health Sciences Centre, Victoria General Hospital, 1278 Tower Road, Ninth floor, Halifax, Nova Scotia B3H 2Y9. Telephone 902-473-7833, fax 902-473-4406, e-mail dleddin@dal.ca

Received for publication January 23, 2008. Accepted January 24, 2008 
A report commissioned by Health Canada (1), noting that waiting lists in Canada were "non-standardized, capriciously organized, poorly monitored, and [...] gravely in need of retooling", called for standardized methods for measuring and reporting waiting times, and for consensus panels to develop procedure-specific criteria for determining priority. In 2004, provincial and federal governments agreed to establish comparable indicators of access to health care and evidencebased benchmarks for medically acceptable wait times for five priority areas: cancer, heart, diagnostic imaging, joint replacements and sight restoration (2). On-line reporting of wait times in these areas is now available in most jurisdictions. However, this is not yet the case for the majority of medical conditions and diagnoses, including digestive diseases, which pose a greater economic burden in Canada than cancer or heart disease (3), and comprise $18.2 \%$ of projected cancer cases and $21.9 \%$ of projected cancer deaths for 2006 (4).

Recognizing the need to address access to care for digestive disease, the Canadian Association of Gastroenterology (CAG) developed a resource plan that involved three complementary initiatives: a detailed census of gastroenterologists providing digestive health care in Canada (5); a multidisciplinary consensus panel in charge of establishing evidence- and expertise-based target maximal wait times for digestive health care (6); and a Practice Audit in Gastroenterology (PAGE) program to measure wait times for digestive disease consultations and procedures (pages 155-60 in the present issue) (7). In the present publication, we report on a subset of the reported wait times (7) that were directly comparable with the target times established by the consensus panel (6). This benchmarking exercise established the extent to which reported total wait times (from referral to procedure completion) meet recommendations (6). The total wait time was evaluated, because it was considered to be the best indicator of the time elapsed before provision of a definitive diagnosis.

\section{METHODS}

Consensus conference on medically acceptable maximal wait times

This multidisciplinary conference, which was organized by the CAG, involved key stakeholders, including representatives from provincial or regional gastroenterology societies, general surgery, internal medicine, family practice, gastroenterology nursing (nonvoting) and relevant CAG committees (6).

Draft statements on maximal target wait times for digestive health care were developed, based on common reasons for referral of adults to a gastroenterologist, an extensive review of the literature and expert opinion, when appropriate. This was supplemented by literature on the relationship of clinical outcomes to timeliness of care, including the likelihood of serious disease for specific presenting signs or symptoms, the impact of different digestive symptoms or disorders on patient quality of life, and the impact of specialist intervention on outcome.

Using a modified Delphi model approach (8), draft statements were revised (9) before the consensus conference, which was held in January 2005, in accordance with generally accepted standards (10). In total, 24 recommendations, related to patients who had been assessed initially by another physician before referral to the specialist, were adopted (Table 1) according to the criterion that more than $50 \%$ of eligible participants had voted that they could be accepted 'completely', 'with some reservation', or 'with major reservation' (9).

\section{TABLE 1}

Overview of recommended maximal wait times by acuity category

Within $24 \mathrm{~h}$
Acute gastrointestinal bleeding (\#1)
Clinical features of ascending cholangitis (\#8)
Acute severe pancreatitis (ERCP within $72 \mathrm{~h}$, if indicated) (\#9)
Severe decompensated liver disease (\#10)
Acute severe hepatitis (\#11)
Esophageal food bolus or foreign body obstruction (\#15)
Within 2 weeks
High likelihood of cancer, based on imaging or physical examination (\#5)
Painless obstructive acute jaundice (\#12)
Severe and/or rapidly progressive dysphagia or odynophagia (\#16)
Clinical features suggestive of active inflammatory bowel disease (\#23)
Within 2 months
Bright red rectal bleeding (\#2)
Documented iron deficiency anemia (\#3)*
One or more positive fecal occult blood tests (\#4)
Chronic viral hepatitis (\#13)
Stable dysphagia that is not severe (\#17)
Poorly controlled reflux/dyspepsia; without (\#18) or with (\#19) alarm
symptoms*
Chronic constipation or chronic diarrhea (\#20)*
New-onset change in bowel habit (\#21)
Chronic unexplained abdominal pain (\#22)
Confirmation of a diagnosis of celiac disease (antibody test) (\#24)
Within 6 months
Chronic gastroesophageal reflux disease for screening endoscopy (\#6)
Screening colonoscopy (\#7)
Persistent (more than six months) unexplained abnormal liver enzyme
(t)

Consensus statement numbers are shown in parentheses. *Recommendation that was compared with the Practice Audit in Gastroenterology data. Data from reference 6

Documentation of actual wait times

'Point-of-care' wait time data were collected using the PAGE program (7), by specialist physicians providing health care to patients with digestive diseases; physicians were eligible to participate if their practice was open to consultations and procedures for new referrals, and if they routinely documented the date on which patients were first referred for consultation. Data, including date of first referral and date of consultation or procedure visit (Table 2), were collected using personal digital assistants (PDAs), on patients seen for consultation, or diagnostic or therapeutic procedures over a one-week period. After audit completion, PDAs were collected and the data were downloaded to the central server/database and checked for validity, duplication and loss using an automated quality control system. Using random manual checks, central server data were validated against the original PDA data for $5 \%$ of audits, to ensure data integrity.

\section{Data analysis}

Data were analysed (YC) to determine total wait times - the time from the patient's first referral to the digestive health care provider until completion of the procedures or tests. Descriptive statistical analysis (SAS version 9.1, SAS Institute 


\section{TABLE 2}

Excerpt of the Practice Audit in Gastroenterology audit questions and possible responses, related to matching of audit data with consensus recommendations

Q12) Does the patient have any of the following alarm symptoms/features (check all that apply)?

a) Abdominal mass

b) Age $>50$ years

c) Dysphagia

d) Occult blood positive

e) Anemia

f) Bloody diarrhea

g) Melena/rectal bleeding

h) Hematemesis

i) Persistent vomiting

j) Jaundice

k) Unexpected weight loss

I) Other

m) None

Q13) Symptoms/signs excluding alarm symptoms you selected previously (check all that apply)

a) Heartburn/reflux

b) Heartburn/reflux despite optimal therapy

c) Odynophagia

d) Chest pain

e) Epigastric pain

f) Dyspepsia

g) Abdominal pain

h) Abdominal pain despite optimal therapy

i) Anorectal pain or discomfort

j) Constipation

k) Constipation alternating with diarrhea

I) Diarrhea

m) Frequent evacuation

n) Sensation of incomplete evacuation

o) Fecal incontinence

p) Mucus in stool

q) Other

r) None

Q14) Examination/test results (check all that apply)
a) Test results normal
b) Abnormal physical exam
c) Abnormal radiologic results
d) Abnormal bloodwork
e) Abnormal endoscopy
f) Other abnormal result
g) None

Q15) Patient's past GI history (check all that apply)
a) Acid/peptic disorder
b) Small intestinal disorder
c) Hepatobiliary disorder
d) IBD
e) Other (non-IBD) colonic disorder
f) Colon cancer
g) Other
h) None

TABLE 2 - CONTINUED

Excerpt of the Practice Audit in Gastroenterology audit questions and possible responses, related to matching of audit data with consensus recommendations

Q18) How concerned are you about the possibility of neoplastic disease in this patient?

a) Not concerned

b) Somewhat concerned

c) Very concerned

Q19) (Listed) below are the reasons for referral you just selected for this patient. From this list please choose the primary/most important reason for referral of the patient.

GI Gastrointestinal; IBD Inflammatory bowel disease; Q Question number

Inc, USA) confirmed that wait times were not normally distributed. Results are therefore presented using the $25 \mathrm{th}, 50 \mathrm{th}$ (median) and 75th percentiles. Results by categorical variables are presented in counts, percentages and $95 \% \mathrm{CIs}$, using the normal approximation of the binomial distribution. No formal statistical comparisons were performed, because this was not a hypothesis-testing study.

Comparison of consensus recommendations and actual wait times

A direct comparison between the 24 clinical scenario-based recommendations produced by the consensus process (6) and the PAGE data (7) identified seven consensus recommendations for which there were detailed data, sufficient to allow an accurate evaluation of timeliness of care (Table 3).

\section{RESULTS}

Of the 5559 audits recorded nationally, consultations alone accounted for 3656 audits (66\%), and visits for procedures (including same-day consultation and procedure) accounted for the remaining 1903 (34\%). Total wait times were determined from the 1903 procedure visit audits in British Columbia $(n=401)$, Alberta $(n=218)$, Saskatchewan $(n=26)$, Manitoba $(n=3)$, Ontario $(n=774)$, Quebec $(n=276)$, New Brunswick $(n=128)$, Nova Scotia $(n=53)$ and Newfoundland $(n=24)$. There were insufficient data for some provinces (ie, less than 24 audits per consensus recommendation) to provide an accurate assessment of wait times or to permit interprovincial comparisons in comparison with consensus conference recommendations (Table 3).

The distributions of wait times were skewed (Figure 1), with total wait times exceeding eight to 30 weeks and 20 to 38 weeks, respectively, for $25 \%$ of patients for whom target wait times were two weeks and two months (Table 4).

The median reported total wait time for 'dyspepsia and associated alarm symptoms' was equal to the target wait time of two months. For all other indications, the median reported total wait time ranged from approximately 1.2 to 7.2 times the target wait time (Table 4). Nationally, the median reported total wait time for patients whose diagnosis was 'probably cancer' was 26 days, while that for patients with features suggestive of inflammatory bowel disease (IBD) was 101 days (compared, in both cases, with the target time of 14 days) (6). The proportion of patients who had undergone consultation and investigation within the target time ranged from $12 \%$ for patients with possible IBD to $51 \%$ for those who had dyspepsia with possible alarm features (Figure 2). Although there was 


\section{TABLE 3}

Criteria for extraction of Practice Audit in Gastroenterology data for comparison with consensus recommendations

Consensus conference recommendation
3) Patients referred with documented iron deficiency anemia
should be seen and if indicated, endoscoped within two months
4) Patients referred with one or more positive fecal occult blood tests
should be seen and if indicated, endoscoped within two months
5) Patients referred because of a high likelihood of cancer, based
on imaging or physical examination should be seen and if indicated,
endoscoped within two weeks
18) Patients referred with poorly controlled reflux symptoms or other
dyspepsia symptoms, but no alarm symptoms, should be seen,
and if indicated, endoscoped within two months
19) Patients referred with dyspepsia and associated alarm symptoms
(eg, vomiting, weight loss, gastrointestinal blood loss) should be
seen and if indicated, endoscoped within two months
20) Patients referred with unexplained chronic diarrhea or chronic
constipation should be seen and if indicated, endoscoped within
two months
23) Patients referred with clinical features highly suggestive of significant
active inflammatory bowel disease should be seen and if indicated,
endoscoped within two weeks

Consensus conference recommendations listed are from reference 6

a suggestion that wait times might differ among provinces, there were too few cases to determine whether these apparent differences were clinically relevant or statistically significant.

\section{DISCUSSION}

The present study is the first published national evaluation of the timeliness of specialist care for patients with digestive diseases, based on a point-of-care measurement of wait times in comparison with national guidelines. With respect to the seven indications evaluated in the present analysis, fewer than one-half of the patients referred for a specialist gastroenterology consultation in Canada received a full evaluation within the target wait time defined by a national consensus conference on the timeliness of care for patients with digestive diseases (6).

The national median total wait time, determined by the PAGE program for 1903 patients from referral to initial investigation, was over 13 weeks; however, the distribution of wait times was highly skewed, with one-quarter of patients waiting more than 29 weeks (7). Judged subjectively by physicians and patients $(11,12)$, these wait times are prolonged, but the availability of the consensus panel recommendations (6) permits an objective evaluation of the timeliness of care for patients with different digestive diseases, and provides an evidence-based context for the national practice audit data (7).

Wait times were protracted, relative to the CAG consensus recommendations (6), regardless of whether patients were considered to require urgent investigation (suspected cancer and gastrointestinal tract bleeding) or not (chronic constipation and diarrhea). Overall, more than $50 \%$ of all patients with digestive diseases waited longer than recommended from referral to investigation (7). This was also the case for patients with any of the seven indications evaluated in the present study; most notably, approximately $85 \%$ of patients with suspected IBD waited longer than recommended before an initial endoscopic investigation was undertaken. Wait times were
Criteria (Table 2) for extraction of 'matching' audits

Anemia (12e) AND abnormal bloodwork (14d)

Occult blood positive (12d)

Abdominal mass (12a) OR unexpected weight loss (12k) OR abnormal physical exam (14b) OR abnormal radiologic results (14c) AND very concerned about the possibility of neoplastic disease in this patient (18c) No alarm symptoms (12m) AND heartburn/reflux despite optimal therapy (13b)

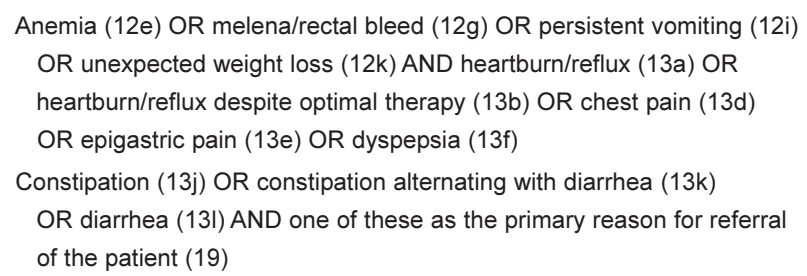

also prolonged relative to benchmarks published by the Canadian Wait Time Alliance (12). For example, one-half of the patients who were judged likely to have cancer waited up to 26 days for a procedure and one-quarter waited more than 56 days, compared with target wait times of 14 days to care for patients with suspected malignancy, and 10 working days until consultation with 10 further working days to treatment for patients requiring radiation therapy (12).

The wait times were markedly extended for patients with probable IBD and unexplained chronic diarrhea or constipation; $25 \%$ of these patients waited more than seven months and 8.9 months, respectively, for a procedure. For IBD patients, early diagnosis and aggressive intervention may reduce the possibility of complications (13) and significant delays in evaluation may therefore, lead to poorer outcomes (14) and an impaired quality of life (15). Constipation and diarrhea are also associated with significant impairment of quality of life (16-18), and delays in diagnosis and therapy are likely to impose a considerable burden on the individual and on society (3). The lengthened wait times for patients with suspected IBD, irritable bowel syndrome, chronic diarrhea and chronic constipation suggest that gastroenterologists prioritize consultations to deal more promptly with patients who should be seen urgently. However, prioritization alone is not sufficient to provide adequate access to care, given that the wait times for urgent and emergency conditions are already prolonged in the opinions of both physicians (6) and patients (11). In a survey of 916 patients who were waiting for a first-time gastroenterology consultation in six cities across Canada, over $96 \%$ reported that the wait for care should be less than three months (versus the national median total wait time of 13 weeks) (7), 79\% reported that it should be less than one month and $40 \%$ reported that it should be less than two weeks (11).

There are several reasons for these prolonged wait times, one being a current shortage of gastroenterologists in Canada compared with many other G7 countries (5). This is of particular 


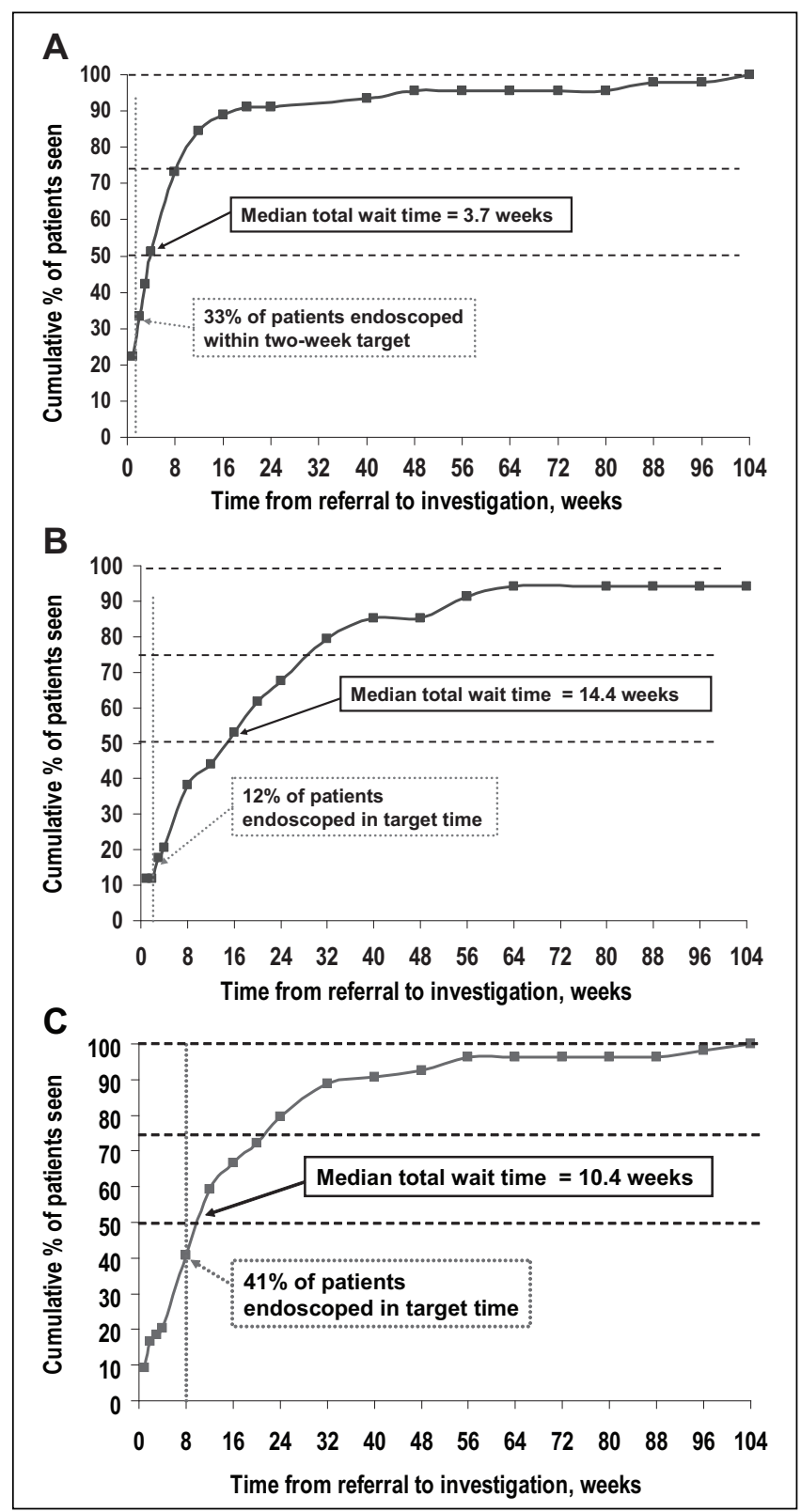

Figure 1) Cumulative percentage of patients seen with probable cancer $(n=45)$ (A); probable inflammatory bowel disease (IBD) ( $n=34)(B)$; and fecal occult blood positive $(n=54)(\mathrm{C})$, compared with consensus conference maximal wait time targets

concern amid projections that one-third of Canadian gastroenterologists ( 180 to 200 of an estimated 550 practising gastroenterologists) will reach retirement age over the next 10 years (19). In addition, although it is estimated that the number of practising gastroenterologists will decline further unless there is a twofold increase in the number of newly trained gastroenterologists over this period, there is no indication of any plans to address this deficit in Canada. For example, although the Ontario government has committed to a significant increase in medical school enrolment, and training and assessment positions for international graduates (20), training positions in gastroenterology remain limited. Given that the time from enrolment in medical school to completion of subspecialty training in gastroenterology is at least 10 years,
TABLE 4

Reported total wait times in relation to consensus conference maximal wait time targets. Regions listed are those with at least 24 audits

\begin{tabular}{lcc}
\hline $\begin{array}{l}\text { Patient group per } \\
\text { consensus recommendation } \\
\text { (number of audits) }\end{array}$ & $\begin{array}{c}\text { Reported total } \\
\text { wait, median, } \\
\text { days }\end{array}$ & $\begin{array}{c}\text { Reported total wait, } \\
\text { 25th-75th percentile, } \\
\text { days }\end{array}$ \\
\hline
\end{tabular}

Target -2 weeks ( 14 days)

High likelihood of cancer based

on imaging or physical exam

National (45)

Ontario (24)

$26 \quad 8-56$

Clinical features highly suggestive of

28

$7-61$

significant active inflammatory

bowel disease

National (34)

101

$35-209$

Target -2 months ( 61 days)

Documented iron deficiency anemia

National (118)

British Columbia (28)

Alberta (24)

Ontario (44)

One or more positive fecal occult blood tests

National (54)

Ontario (29)

Dyspepsia and associated alarm symptoms

National (109)

British Columbia (26)

Ontario (52)

Poorly controlled reflux symptoms or other dyspepsia symptoms, but no alarm symptoms

National (43)

126

$42-225$

Unexplained chronic diarrhea or

chronic constipation

National (126)

British Columbia (25)

Ontario (54)

$\begin{array}{ll}71 & 19-142 \\ 55 & 22-191 \\ 79 & 15-155 \\ 56 & 18-114\end{array}$

73

$36-148$

$46-140$

60

23-140

22-155

$30-140$

67

141

$68-264$

$80-394$

$77-222$

human resource shortages will probably constitute a barrier to any significant reductions in wait times for digestive health care. Indeed, the anticipated increase in demand for colonoscopy for colon cancer screening is likely to lengthen wait times still further; limited access to digestive disease consultations and investigations may lead to an increase in alternative, less appropriate investigations (21-23), with the potential for diminished diagnostic accuracy, suboptimal patient care and increased costs. Alternative care models involving primary care physician endoscopists, nurse practitioners, physician extenders such as nurse endoscopists (24) and gastroenterology physician assistants may shorten wait times for consultation and procedures, but these solutions will also require time to implement and they will not provide a substitute for specialist gastroenterologists.

Prolonged wait times may be shortened if interventions are developed to ensure more efficient utilization of the current, limited resources. The use of standard referral forms for family physicians, tailored to the health care deficits identified, for example, by the PAGE program $(7,25)$ and the implementation 


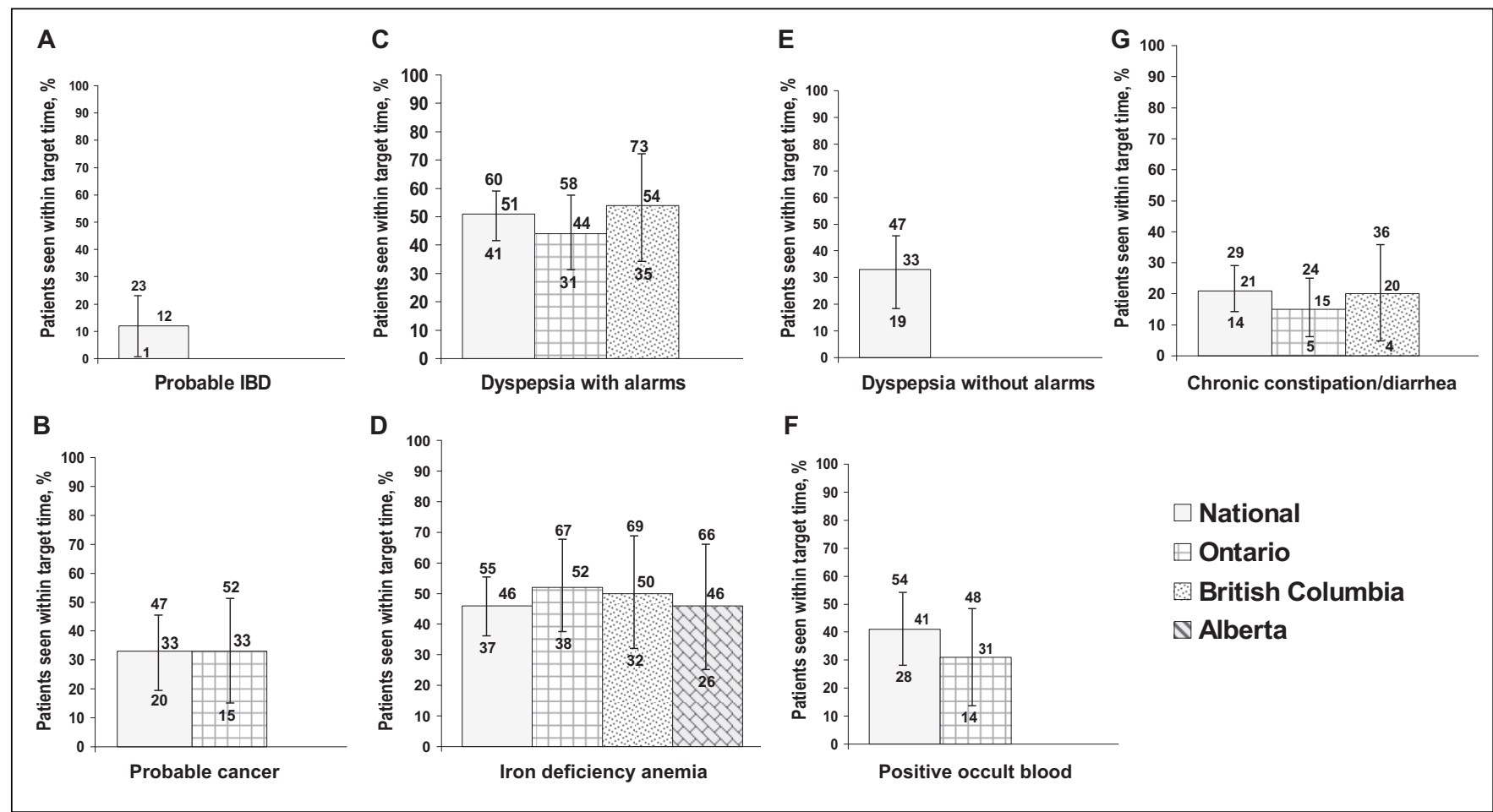

Figure 2) Percentage of patients seen within consensus wait time targets (bars) and 95\% CIs (error bars) for regions with at least 24 audits. A Probable inflammatory bowel disease (IBD); B Probable cancer; C Dyspepsia with alarm symptoms; D Iron deficiency anemia; E Dyspepsia without alarm symptoms; F Positive occult blood; G Chronic constipation and diarrhea

of evidence-based referral and management guidelines for digestive diseases would be expected to reduce inappropriate specialist referral and investigations, resulting in more timely access for patients with digestive disorders and better, more cost-effective care. The implementation in Canada of current programs to define, measure and improve the quality and timeliness of endoscopy should also lead to improvements in resource utilization and access to care for digestive diseases (26).

The use of a 'point-of-care' practice audit methodology allows for direct documentation of the precise dates of referral, consultation and initial investigative procedure, along with other patient data. Unlike large administrative databases, the data are available to individual institutions or physicians, thus enabling them to implement changes in response to the findings of their practice audit $(7,24)$. Participants can also review their practice again after an intervention to determine the effect of any changes that may have been made. Because the data relate to a subset of Canadian gastroenterologists who were willing to undertake a practice audit, they may not be fully generalizable. Nonetheless, they do reflect the practice of nearly one-third of Canadian gastroenterologists (19). For the present study, the reported wait times (7) were directly comparable to target wait times (6) for only seven indications; this was because the practice audit data collection tool had to be developed before the completion of the consensus process. However, the methodology of the PAGE program provides a basis for collecting the more targeted data necessary to evaluate differences in wait times with respect to geographical regions or specific diagnoses and procedures, to assess the effects of interventions and to define the needs for future interventions.
The consensus statements do not represent a formal standard of care but rather, benchmarks or goals against which current care delivery may be compared. They were intended to be an initial step toward understanding the barriers to delivery of gastroenterology care, development of interventions to address key system bottlenecks, and evaluation of outcomes achieved by these interventions.

\section{CONCLUSIONS}

The present study confirms that wait times for access to digestive health care are prolonged compared with published recommendations $(6,12)$ and that the prolonged wait times are evident regardless of whether the patients' symptoms require urgent or emergency evaluation, or whether they are considered to suffer from a chronic, nonurgent condition. Delivery of timely health care to patients with digestive diseases, including those with gastrointestinal cancers, will require a systematic review of the reasons for the current deficit. Short-term and long-term interventions will be required to address these causes, including the training and appointment of additional gastroenterologists and other digestive health care professionals; providing them with the resources needed to support their work; the development of strategies to optimize efficient resource utilization; the implementation of appropriate care guidelines and patient education initiatives; and targeted outcomes research to evaluate any interventions. In this context, the PAGE program provides an audit mechanism that can be used to monitor digestive health care delivery and guide interventions.

SOURCES OF SUPPORT: The Canadian Association of Gastroenterology. 


\section{REFERENCES}

1. Health Canada. Waiting Lists and Waiting Times for Health Care in Canada. More Management!! More Money?? Summary Report July 1998. <http://www.hc-sc.gc.ca/ahcasc/media/nr-cp/1998/1998_50_e.html> (Version current at January 24, 2008).

2. Health Canada. Health Care Renewal. A 10-Year Plan to Strengthen Health Care. September 16, 2004. <http:/www.hcsc.gc.ca/hcs-sss/delivery-prestation/fptcollab/2004-fmm-rpm/nrcp_9_16_2_e.html> (Version current at January 24, 2008).

3. Beck IT. Disproportion of economic impact, research achievements and research support in digestive diseases in Canada. Clin Invest Med 2001;24:12-36

4. Canadian Cancer Society/National Cancer Institute of Canada. Canadian Cancer Statistics 2006. <http://www.cancer.ca/vgn/ images/portal/cit_86751114/31/21/935505792cw_2006stats_en.pdf. pdf $>$ (Version current at January 24, 2008).

5. Moayyedi P, Tepper J, Hilsden R, Rabeneck L. International comparisons of manpower in gastroenterology Am J Gastroenterol 2007;102:478-81.

6. Paterson WG, Depew WT, Paré P, et al. Canadian consensus on medically acceptable wait times for digestive health care. Can J Gastroenterol 2006;20:411-23.

7. Armstrong D, Barkun ANG, Chen Y, et al. Access to specialist gastroenterology care in Canada: The Practice Audit in Gastroenterology (PAGE) Wait Times Program. Can J Gastroentero 2008;22:155-60.

8. Dalkey N. An experimental study of group opinion. The Delphi Method. Futures 1969:408-26.

9. Goldbloom R, Battista RN. The periodic health examination: 1. Introduction. CMAJ 1986;134:721-3.

10. Lomas J. Words without action? The production, dissemination, and impact of consensus recommendations. Annu Rev Public Health 1991;12:41-65.

11. Paterson WG, Barkun AN, Hopman WM, et al. Wait times for GI consultation in Canada: The patient perspective. Can J Gastroenterol 2006;20(Suppl A):58A. (Abst)

12. Canadian Medical Association, Wait Time Alliance for Timely Access to Health Care. It's about time! Achieving benchmarks and best practices in wait time management. Final report by the Wait Time Alliance for Timely Access to Health Care, August 2005. <http://www.cma.ca/multimedia/CMA/Content_Images/Inside_cma /Media_Release/pdf/2005/wta-final.pdf > (Version current at January 24, 2008).
13. D'Haens G. Mucosal healing in pediatric Crohn's disease: The goal of medical treatment. Inflamm Bowel Dis 2004;10:479-80.

14. Markowitz J, Grancher K, Kohn N, Lesser M, Daum F. A multicenter trial of 6-mercaptopurine and prednisone in children with newly diagnosed Crohn's disease. Gastroenterology 2000;119:895-902.

15. Irvine EJ. Quality of life issues in patients with inflammatory bowel disease. Am J Gastroenterol 1997;92(12 Suppl):18S-24S.

16. Watson A, Samore MH, Wanke CA. Diarrhea and quality of life in ambulatory HIV-infected patients. Dig Dis Sci 1996;41:1794-800.

17. Lubeck DP, Bennett CL, Mazonson PD, Fifer SK, Fries JF. Quality of life and health service use among HIV-infected patients with chronic diarrhea. J Acquir Immune Defic Syndr 1993;6:478-84.

18. Irvine EJ, Ferrazzi S, Paré P, Thompson WG, Rance L. Healthrelated quality of life in functional GI disorders: Focus on constipation and resource utilization. Am J Gastroenterol 2002;97:1986-93.

19. Moayyedi P. Access to Digestive Health in Canada I. Human Resources in Canada. Canadian Digestive Diseases Week. Banff, February 24 to 26, 2006.

20. Government of Ontario Ministry of Health and Long-Term Care. McGuinty Government Launches New Health Human Resources Strategy. <http://ogov.newswire.ca/ontario/GPOE/2006/05/03/ c3192.html?lmatch=\&lang=_e.html $>($ Version current at January 24, 2008).

21. Veldhuyzen van Zanten SJ, Flook N, Chiba N, et al. An evidencebased approach to the management of uninvestigated dyspepsia in the era of Helicobacter pylori. Canadian Dyspepsia Working Group. CMAJ 2000;162(12 Suppl):S3-23.

22. Armstrong D, Marshall JK, Chiba N, et al. Canadian Consensus Conference on the management of gastroesophageal reflux disease in adults - update 2004. Can J Gastroenterol 2005;19:15-35.

23. Leddin D, Hunt R, Champion M, et al. Canadian Association of Gastroenterology and the Canadian Digestive Health Foundation: Guidelines on colon cancer screening. Can J Gastroenterol 2004;18:93-9.

24. Rabeneck L, Paszat LF. Colorectal cancer screening in Canada: Why not consider nurse endoscopists? CMAJ 2003;169:206-7.

25. Armstrong D, Hollingworth R, Gardiner T, et al. Practice Audit in Gastroenterology (PAGE) program: A novel approach to continuing professional development. Can J Gastroenterol 2006;20:405-10.

26. NHS. Global Rating Scale for Endoscopy. <http://www.grs.nhs.uk/ default.aspx $>$ (Version current at January 24, 2008). 


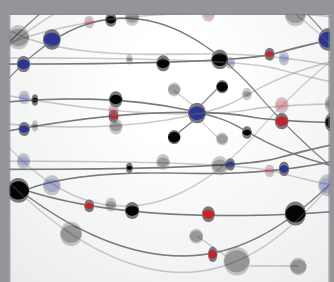

The Scientific World Journal
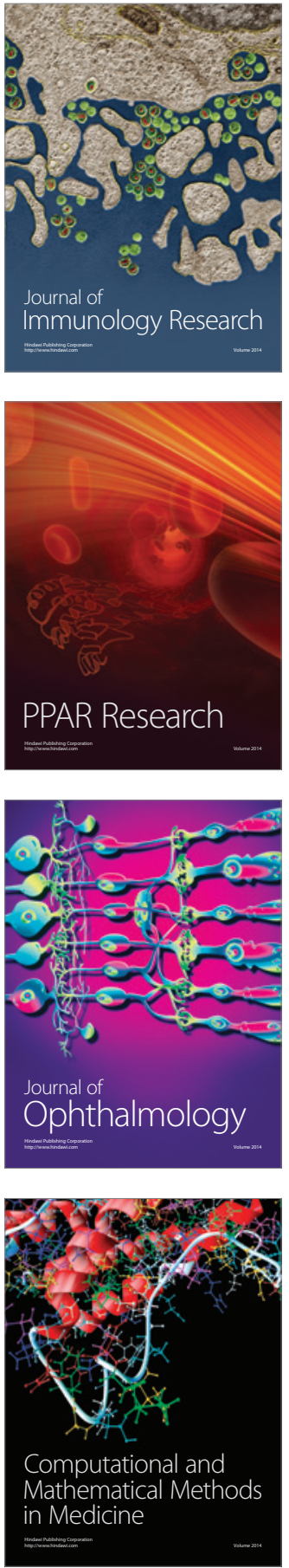

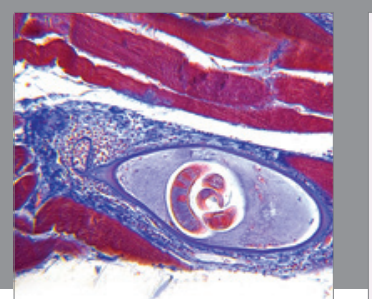

Gastroenterology Research and Practice

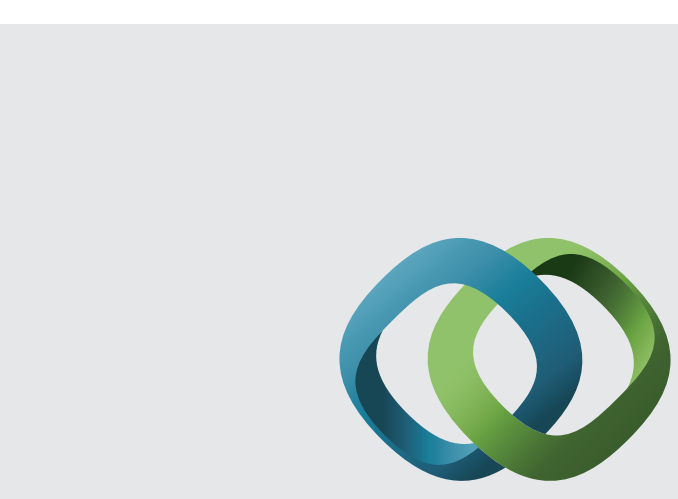

\section{Hindawi}

Submit your manuscripts at

http://www.hindawi.com
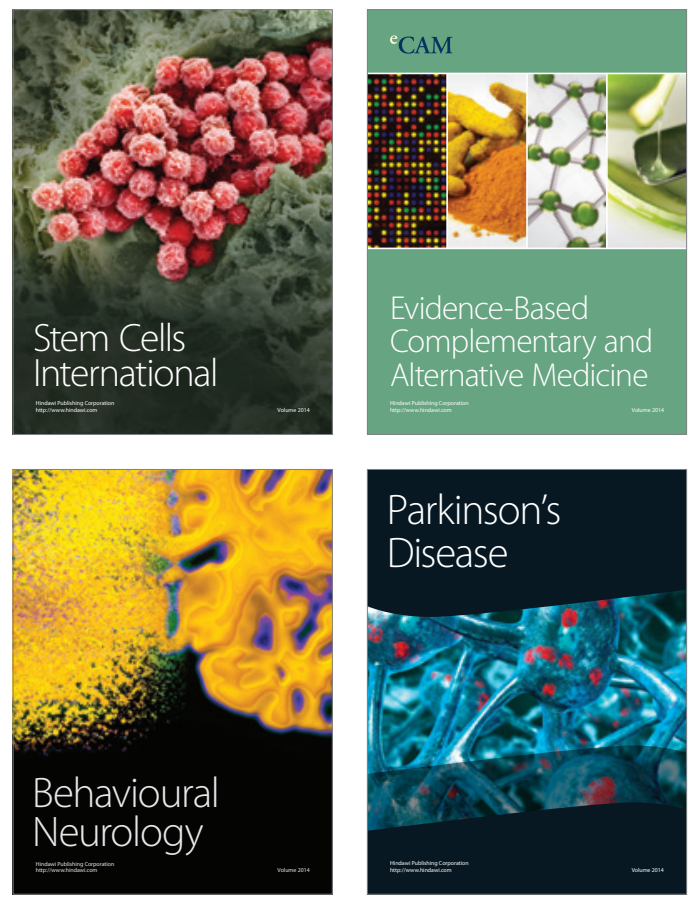
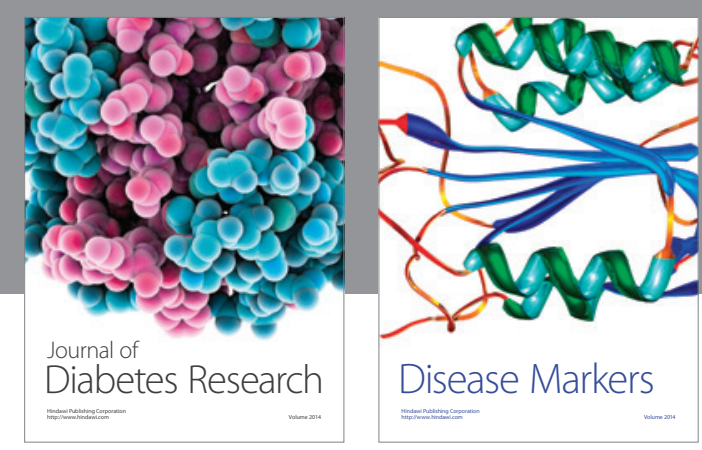

Disease Markers
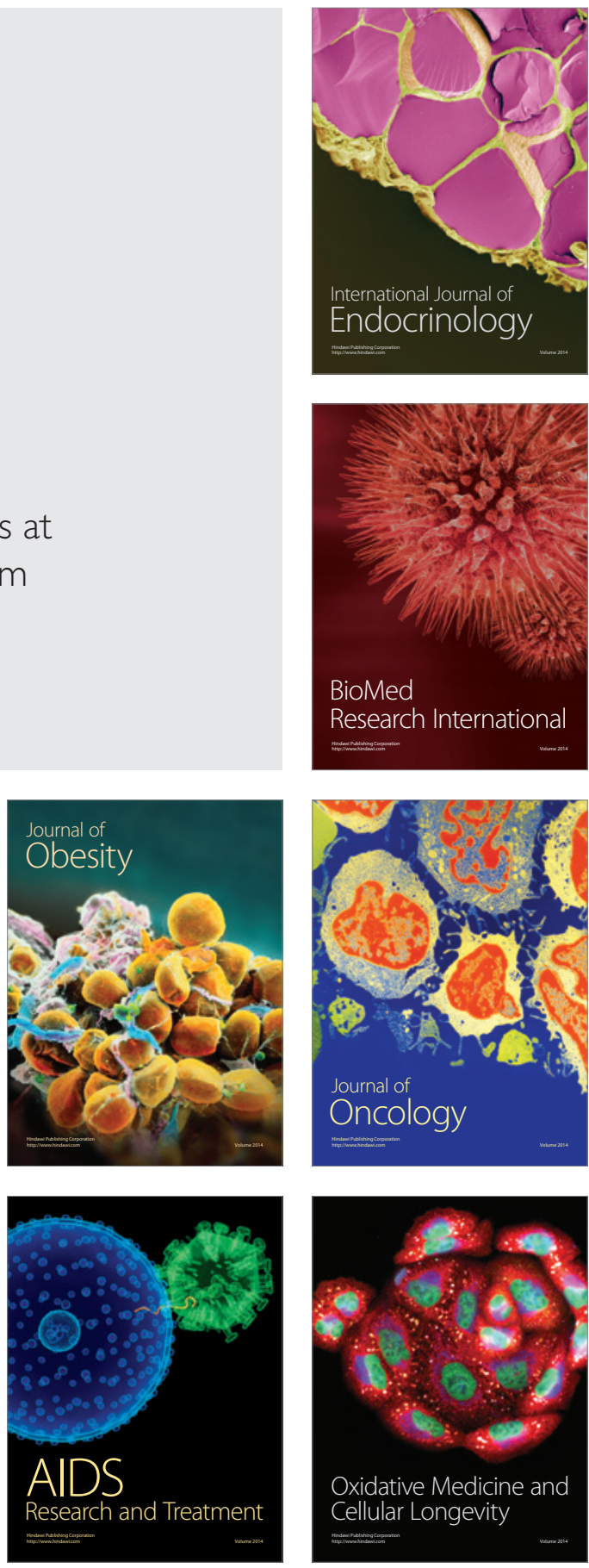